\title{
The DHODH Inhibitor Brequinar is Synergistic with ENT1/2 Inhibitors
}

Christine R. Cuthbertson, Hui Guo, Armita Kyani, Joseph T. Madak, Zahra Arabzada, Nouri Neamati*

Department of Medicinal Chemistry, College of Pharmacy and the Rogel Cancer Center, North Campus Research Complex, 1600 Huron Parkway, University of Michigan, Ann Arbor, MI, 48109, United States

\section{Table of Contents:}

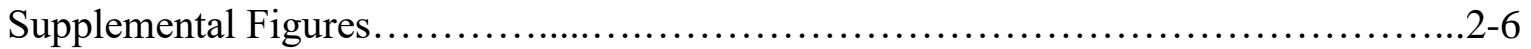

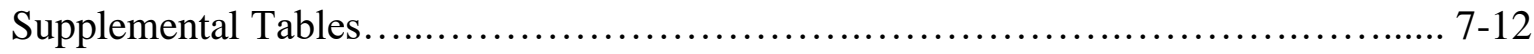

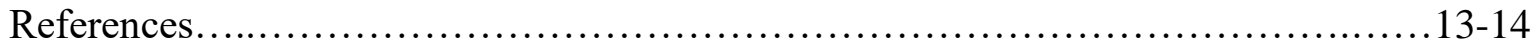




\section{Supplemental Figures}

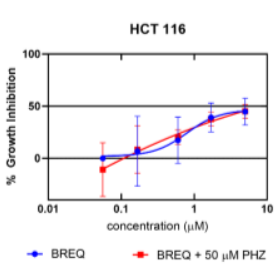

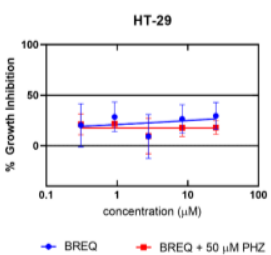

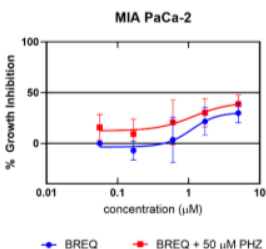

D

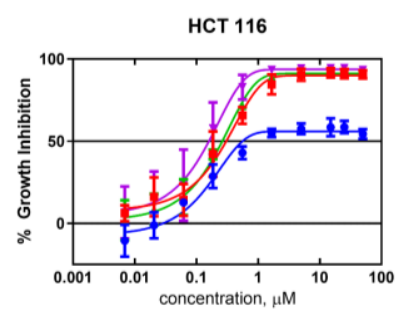

\begin{tabular}{lc}
\hline Treatment & $\mathrm{IC}_{50}(\mu \mathrm{M})$ \\
\hline Breq alone & $0.230 \pm 0.065$ \\
\hline Breq $+0.5 \mu \mathrm{M} \mathrm{DPM}$ & $0.259 \pm 0.075$ \\
\hline Breq $+5 \mu \mathrm{M}$ DPM & $0.226 \pm 0.018$ \\
\hline Breq $+25 \mu \mathrm{M}$ DPM & $0.145 \pm 0.083$ \\
\hline
\end{tabular}

$\rightarrow$ BREQ

- $\mathrm{BREQ}+5 \mu \mathrm{M} D \mathrm{DPM}$

- BREQ + $0.5 \mu \mathrm{M} \mathrm{DPM} \rightarrow \mathrm{BREQ}+25 \mu \mathrm{M} \mathrm{DPM}$

E

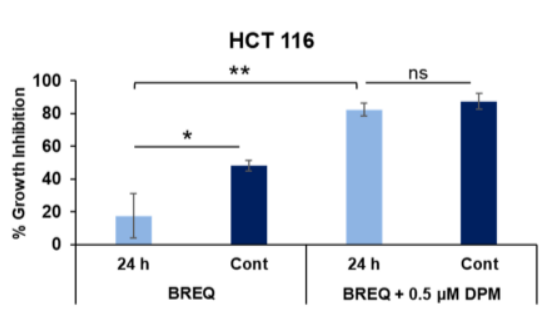

$\mathbf{F}$

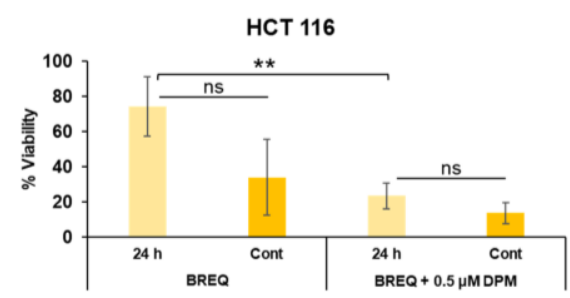

Figure S-1: (A-C) PHZ does not affect cytotoxicity of BREQ. (D) High concentrations of DPM do not shift BREQ's IC ${ }_{50}$. (E-F) BREQ + DPM elicits cell growth inhibition through a cytotoxic and apoptotic mechanism as measured by the (E) MTT and (F) APOSensor assays. 
A

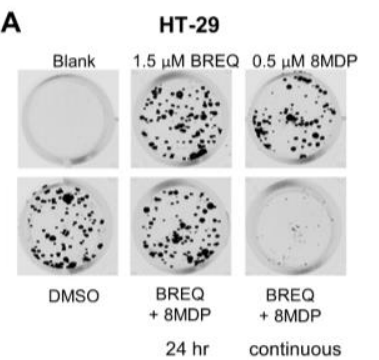

D

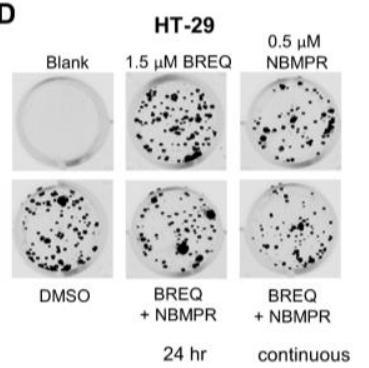

G

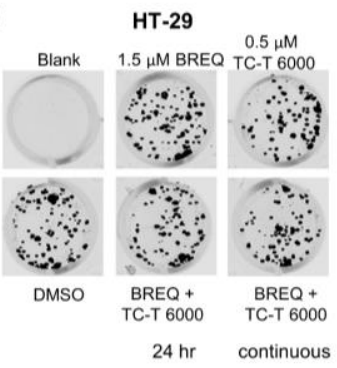

J

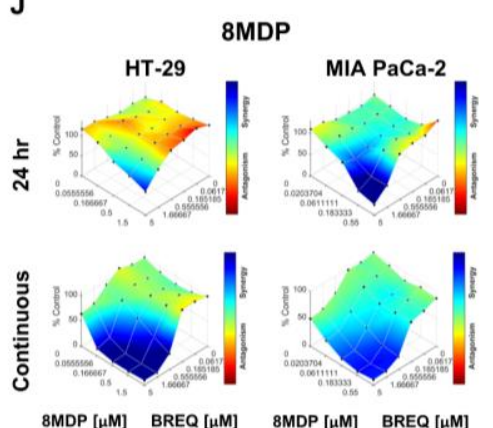

B

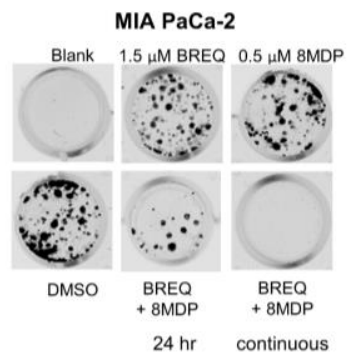

E

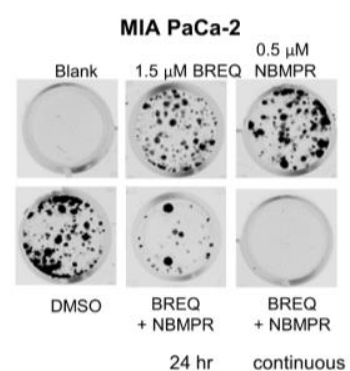

H

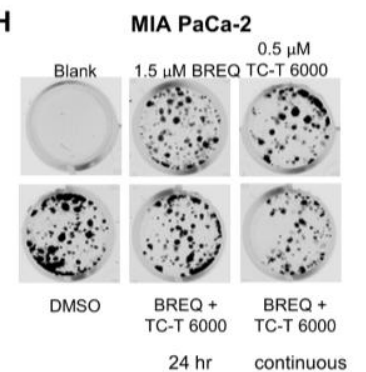

K
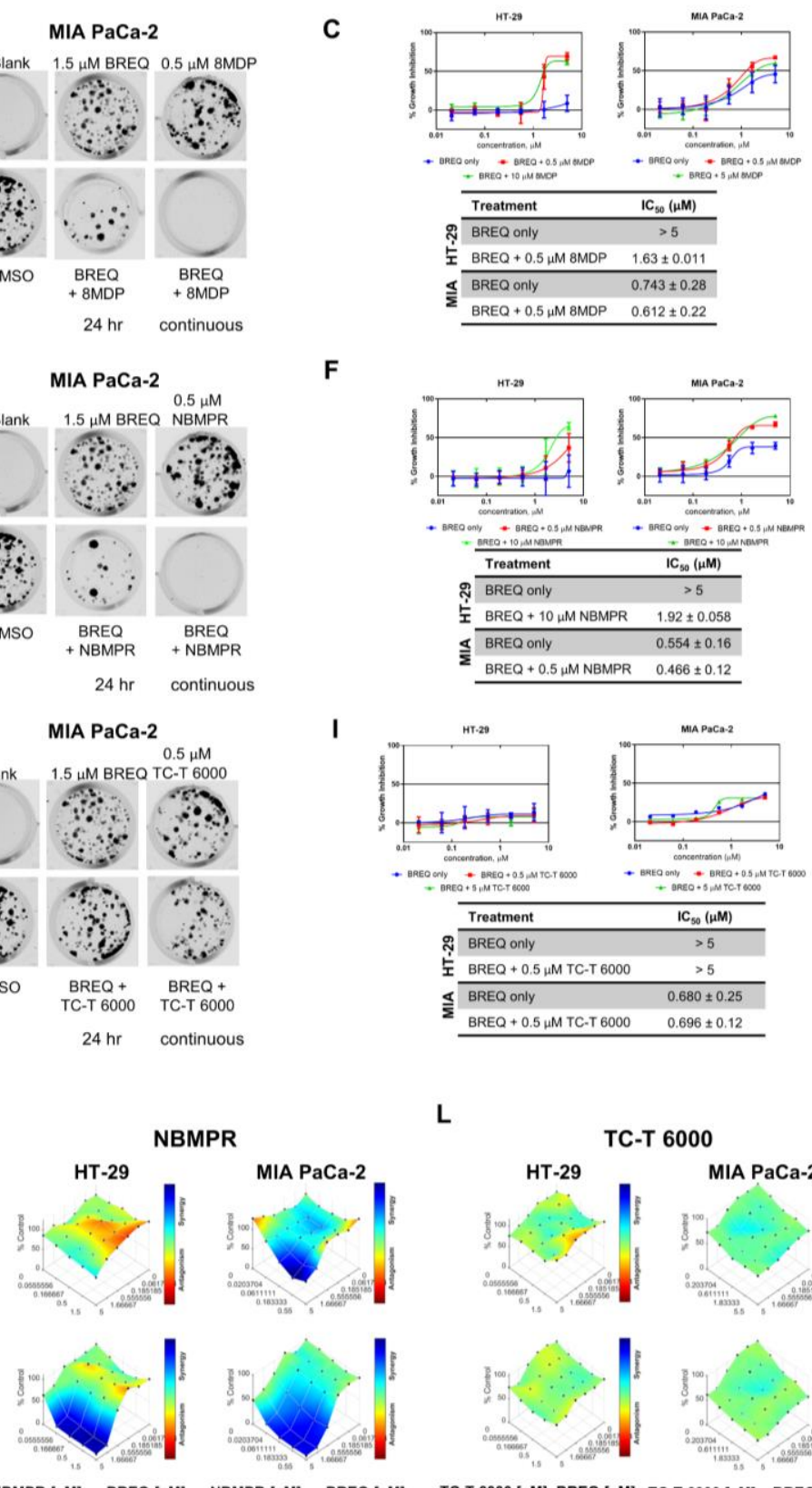

F

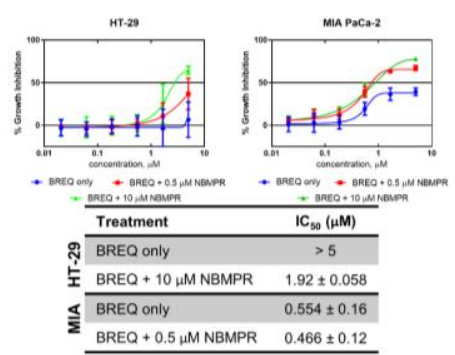

I

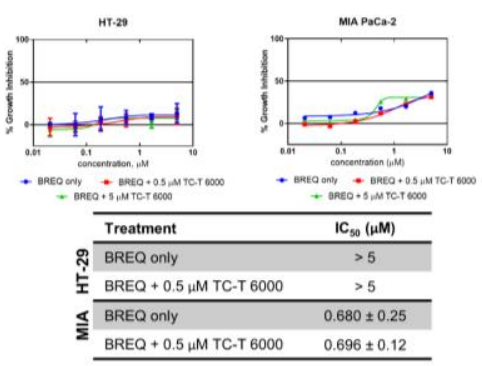

L

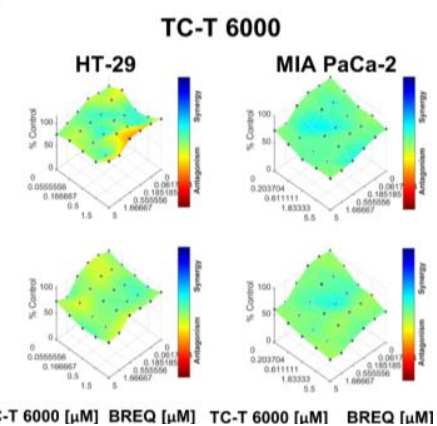

Figure S-2: BREQ is synergistic with ENT1/2 but not ENT4 inhibitors in HT-29 and MIA PaCa2. (A, D, G) CFA at single doses in HT-29. (B, E, H) CFA at single doses in MIA PaCa-2. (C) and MTT IC 50 curves of BREQ + 8MDP. (F) MTT IC 50 curves of BREQ + NBMPR. (I) MTT IC 50 curves of BREQ + TC-T 6000. (A, B, D, E, G, H) Continuous and $24 \mathrm{~h}$ designations are for combinations only; single drugs are continuous treatments. (J-L) Bliss synergy plots using CFA data. 
A

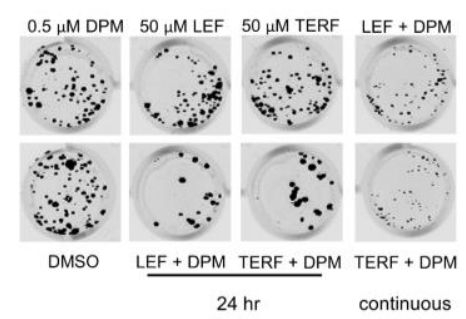

D

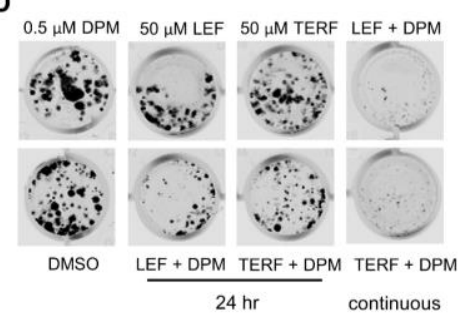

B

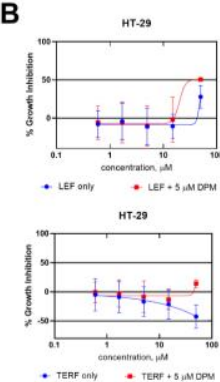

E

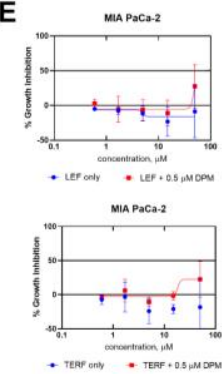

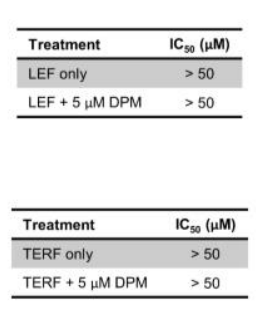

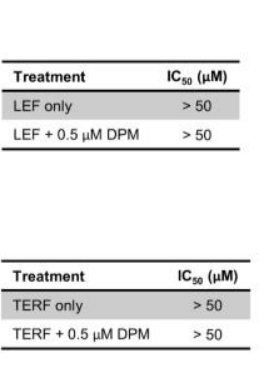

C

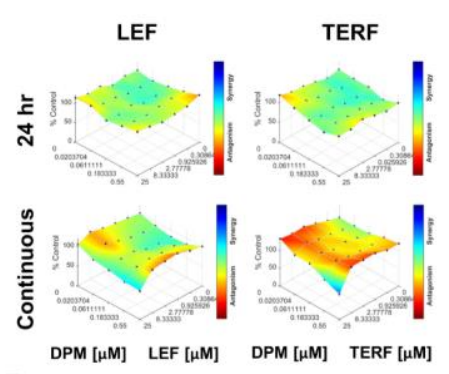

$\mathbf{F}$

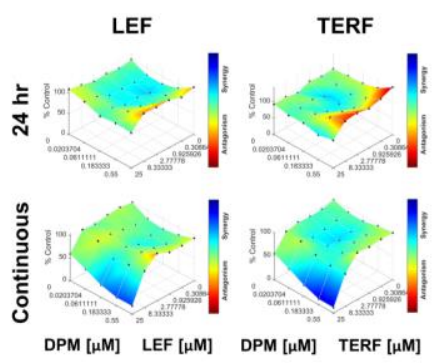

Figure S-3: LEF and TERF are synergistic with DPM in HT-29 (A-C) and MIA PaCa-2 (D-F). (A, D) CFA at single doses. Continuous and $24 \mathrm{~h}$ designations are for combinations only; single drugs are continuous treatments. $(\mathrm{B}, \mathrm{E}) \mathrm{IC}_{50}$ dependence of LEF or TERF in presence of DPM in the MTT assay. (C, F) Bliss synergy plots using CFA data. 
A

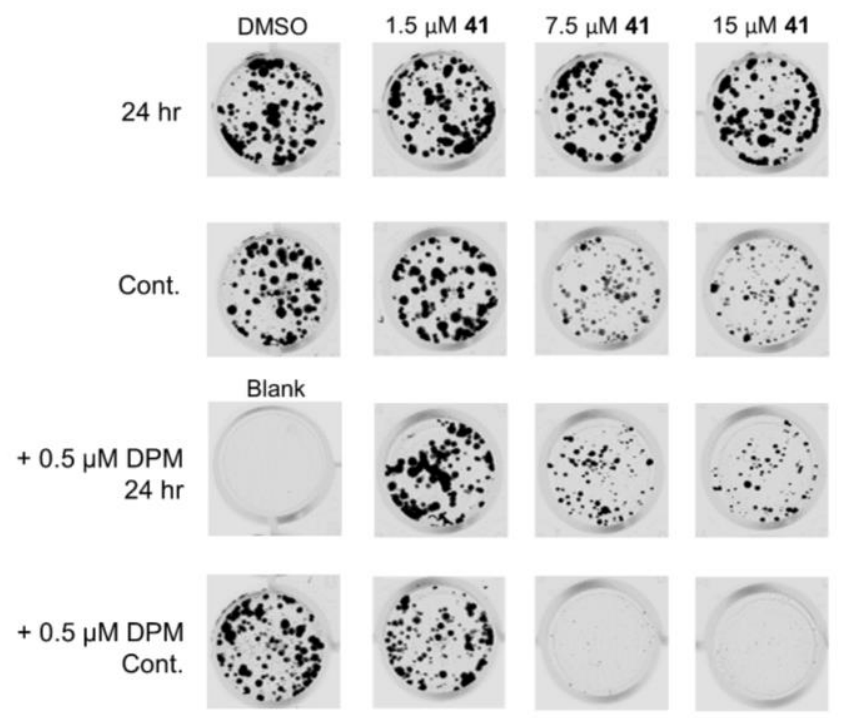

B

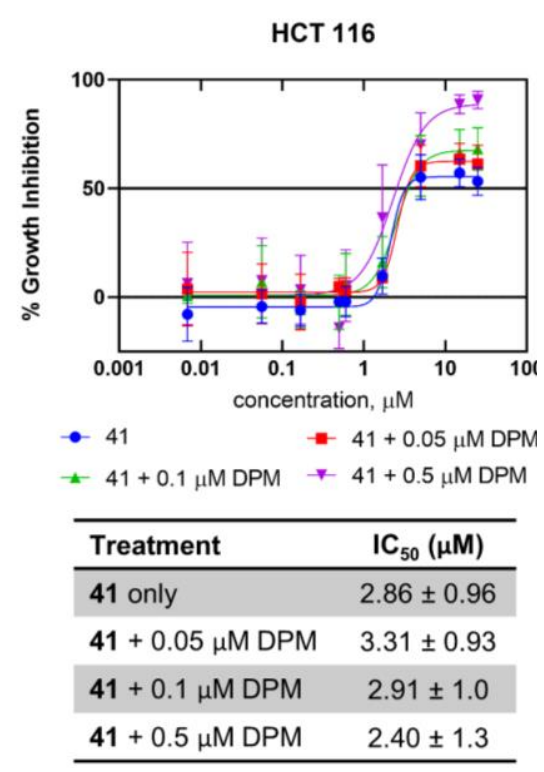

Figure S-4: DHODH inhibitor 41 is synergistic with DPM in HCT 116. (A) CFA at single doses. (B) $\mathrm{IC}_{50}$ dependence of $\mathbf{4 1}$ in presence of DPM in the MTT assay. 
A

\begin{tabular}{lll}
\hline Group & Dose & Solution \\
\hline DPM & $10 \mathrm{mg} / \mathrm{kg}$ & $10 \%$ DMSO, 50\% PEG400, 40\% Saline \\
\hline 41 & $10 \mathrm{mg} / \mathrm{kg}$ & $10 \%$ DMSO, 50\% PEG400, 40\% Saline \\
\hline $\begin{array}{l}\text { DPM + } \\
\mathbf{4 1}\end{array}$ & $\begin{array}{l}10 \mathrm{mg} / \mathrm{kg} \\
10 \mathrm{mg} / \mathrm{kg}\end{array}$ & $10 \%$ DMSO, 50\% PEG400, 40\% Saline \\
\hline
\end{tabular}

C

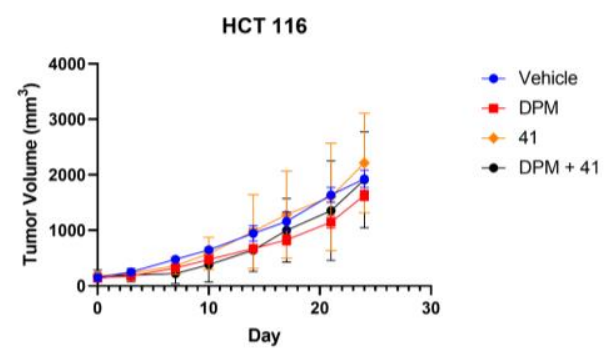

B

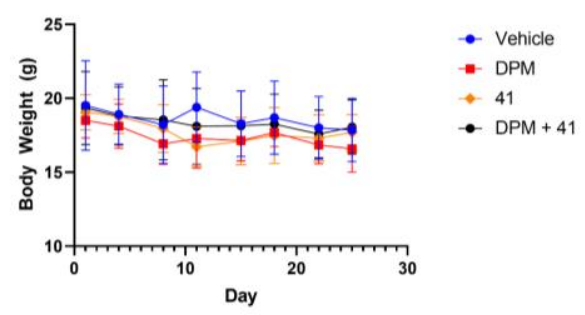

D

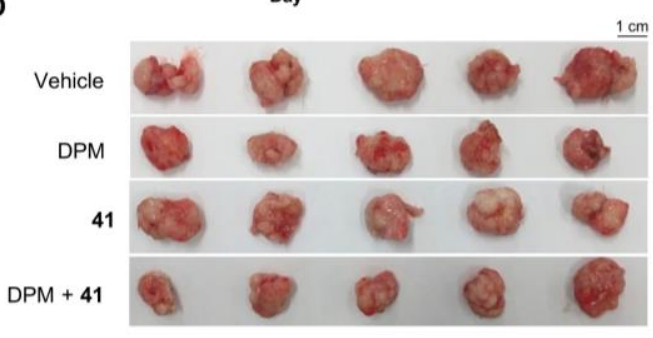

Figure S-5: Anticancer effect of DPM+41 in a mouse xenograft model $(n=5$, mean \pm SEM). (A) Formulations of DPM and 41. (B) Body weight change throughout the study. (C) Tumor volume of each group. (D) Harvested tumors after sacrifice. 
Table S-1: DHODH, CNT, and ENT inhibitors used in this study

\begin{tabular}{|c|c|c|c|c|}
\hline Compound & Structure & Target & Activity & Status $^{a}$ \\
\hline \multirow[b]{2}{*}{ BREQ } & & & $\mathrm{K}_{\mathrm{i}}=25 \mathrm{nM}^{l}$ & Not FDA-approved \\
\hline & & DHODH & $\begin{array}{l}\mathrm{IC}_{50}=6-10 \\
\mathrm{nM}^{2}\end{array}$ & $\begin{array}{l}\text { AML } \\
\text { Phase IA/IIB } \\
\text { (NCT03760666) }\end{array}$ \\
\hline \multirow{8}{*}{ LEF } & & & & $\begin{array}{l}\text { FDA-approved for } \\
\text { rheumatoid and } \\
\text { psoriatic arthritis }\end{array}$ \\
\hline & & & & $\begin{array}{l}\text { Breast cancer } \\
\text { Phase I/II } \\
\text { (NCT03709446) }\end{array}$ \\
\hline & & & & $\begin{array}{l}\text { Prostate cancer } \\
\text { Phase II/III } \\
\text { (NCT00004071) }\end{array}$ \\
\hline & & DHODH & $\mathrm{K}_{\mathrm{i}}=4.6 \mu \mathrm{M}^{3}$ & $\begin{array}{l}\text { Henoch-Schoenlein } \\
\text { purpura nephritis } \\
\text { Phase II } \\
\text { (NCT02532777) }\end{array}$ \\
\hline & & & & $\begin{array}{l}\text { Myasthenia gravis } \\
\text { Phase III } \\
\text { (NCT01727193) }\end{array}$ \\
\hline & & & & $\begin{array}{l}\text { Polymyalgia } \\
\text { rheumatica } \\
\text { Phase III } \\
\text { (NCT03576794) }\end{array}$ \\
\hline & & & & $\begin{array}{l}\text { Nephropathy } \\
\text { Phase IV } \\
\text { (NCT04020328) }\end{array}$ \\
\hline & & & & IgG4-RD \\
\hline
\end{tabular}


Phase IV

(NCT03715699 and

NCT02703194)

Takayasu's arteritis

(NCT02981979 and

NCT03893136)

Multiple myeloma

Phase II

(NCT02509052)

HIV

Phase I

(NCT00101374)

Uveitis

Phase II

(NCT00001863)

Anaplastic

astrocytoma

Phase II

(NCT00003775)

Systemic lupus

erythematosus

Phase II

(NCT00637819);

Phase II/III

(NCT00268567)

\begin{tabular}{lll} 
TERF & $\mathrm{DHODH}_{\mathrm{i}}=2.7 \mu \mathrm{M}^{3}$ & $\begin{array}{l}\text { FDA-approved for } \\
\mathrm{IC}_{50}=230 \\
\mathrm{nM}^{4}\end{array}$ \\
\hline
\end{tabular}




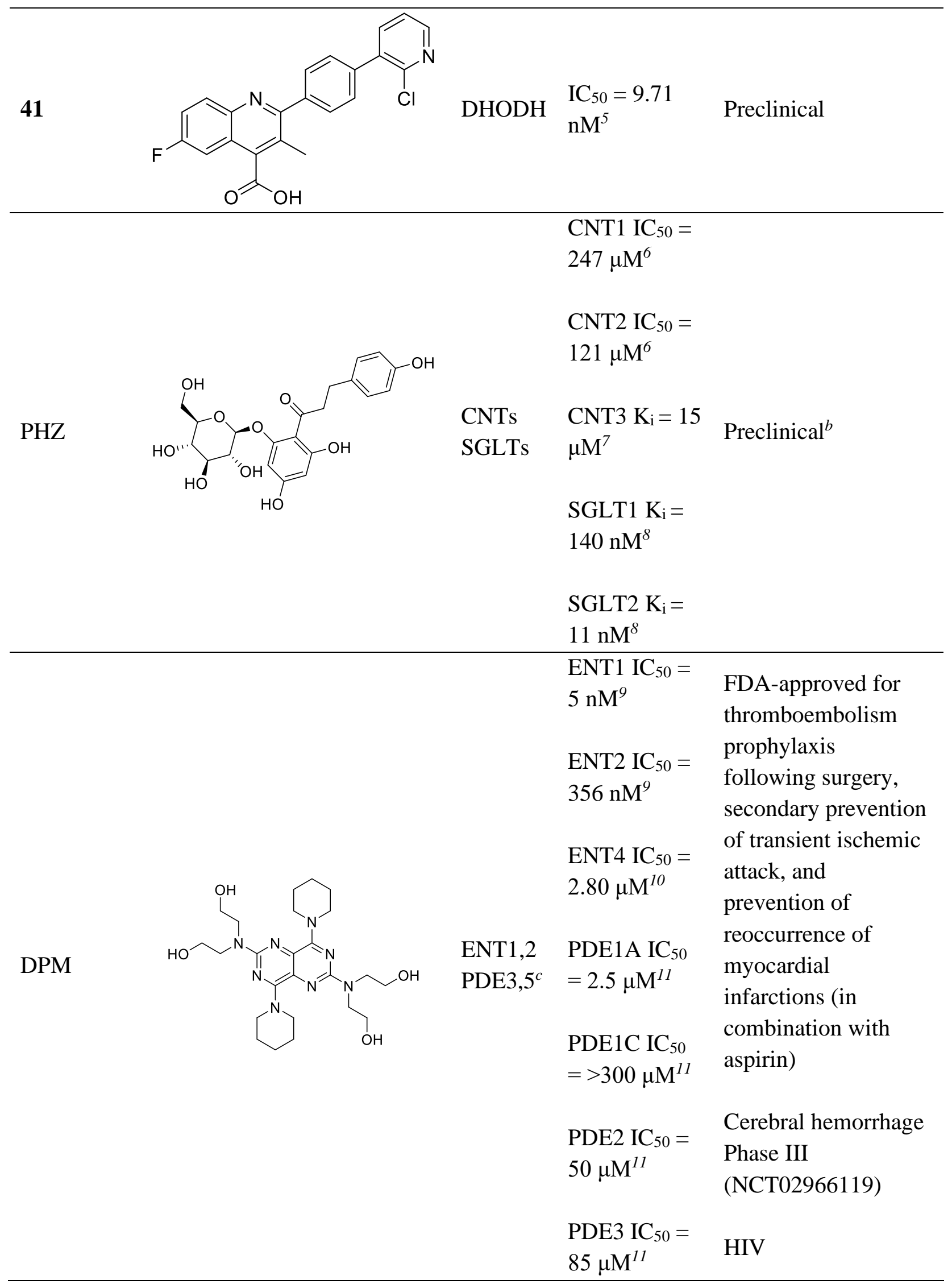




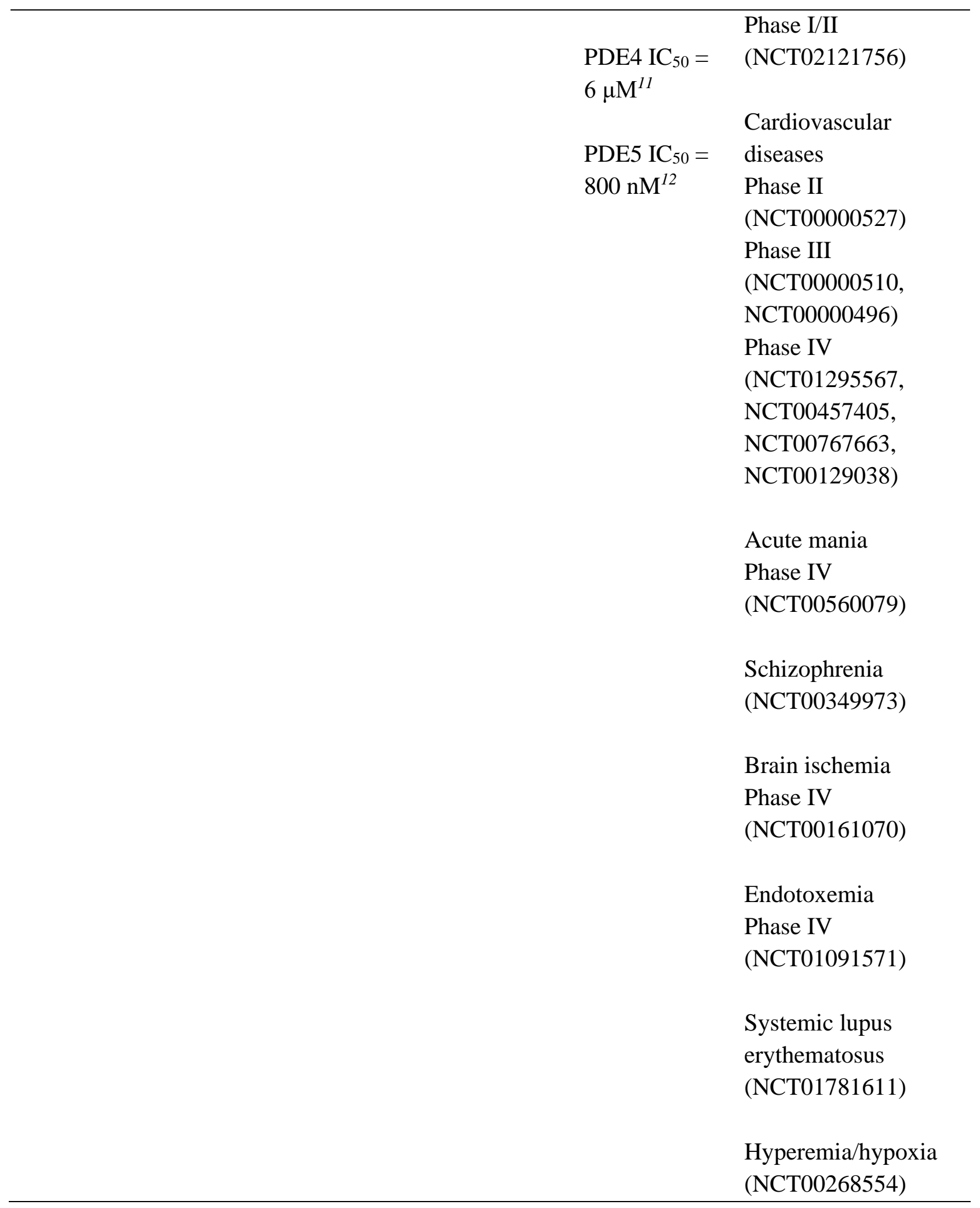




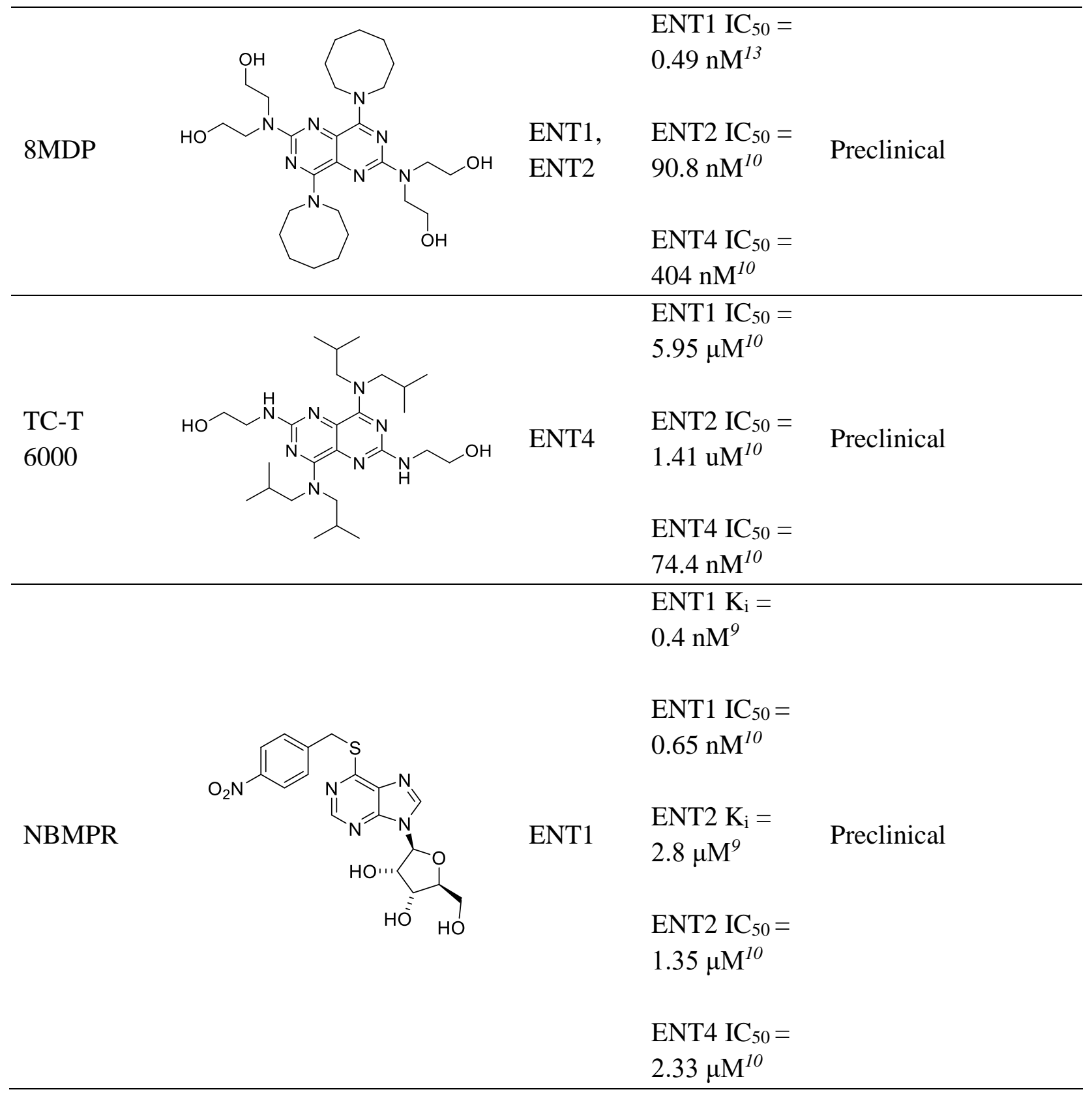

${ }^{a}$ Source: clinicaltrials.gov, for recruiting, active, not recruiting, or completed, as single agents or in addition to standard-of-care.

${ }^{b}$ Found to be unsuitable for people but is still used as a probe. ${ }^{14}$

${ }^{c}$ Phosphodiesterase isoforms that are responsible for the cardiovascular effects. ${ }^{15}$ 
Table S-2: Summary of MTT and continuous-treatment CFA synergy combination results for HCT 116

\begin{tabular}{l|cccc|cccc}
\multicolumn{9}{c}{ MTT } \\
\hline Compound & BREQ & LEF & TERF & $\mathbf{4 1}$ & BREQ & LEF & TERF & $\mathbf{4 1}$ \\
\hline PHZ & no & NT $^{a}$ & NT & NT & no & NT & NT & NT \\
DPM & yes & yes & yes & yes & yes & yes & yes & yes \\
8MDP & yes & NT & NT & NT & yes & NT & NT & NT \\
TC-T 6000 & no & NT & NT & NT & no & NT & NT & NT \\
NBMPR & yes & NT & NT & NT & yes & NT & NT & NT \\
\hline${ }^{a}$ NT = not tested & & & & & & &
\end{tabular}

Table S-3: Summary of MTT synergy combination results for HT-29 and MIA PaCa-2

\begin{tabular}{l|ccc|ccc}
\multicolumn{4}{c}{ HT-29 } & \multicolumn{3}{c}{ MIA PaCa-2 } \\
\hline Compound & BREQ & LEF & TERF & BREQ & LEF & TERF \\
\hline PHZ & no & NT $^{a}$ & NT & no & NT & NT \\
DPM & yes & yes & no & yes & no & no \\
8MDP & yes & NT & NT & yes & NT & NT \\
TC-T 6000 & no & NT & NT & no & NT & NT \\
NBMPR & yes & NT & NT & yes & NT & NT \\
\hline
\end{tabular}

${ }^{a} \mathrm{NT}=$ not tested

Table S-4: Summary of CFA synergy combination results for continuous treatments in HT29 and MIA PaCa-2

\begin{tabular}{l|ccc|ccc}
\multicolumn{3}{c}{ HT-29 } & \multicolumn{3}{c}{ MIA PaCa-2 } \\
\hline Compound & BREQ & LEF & TERF & BREQ & LEF & TERF \\
\hline PHZ & no & NT $^{a}$ & NT & no & NT & NT \\
DPM & yes & yes & yes & yes & yes & yes \\
8MDP & yes & NT & NT & yes & NT & NT \\
TC-T 6000 & no & NT & NT & no & NT & NT \\
NBMPR & yes & NT & NT & yes & NT & NT \\
\hline
\end{tabular}

${ }^{a} \mathrm{NT}=$ not tested

Table S-5: Permeability predictions as calculated using the PerMM server ${ }^{16,17}$

\begin{tabular}{l|ccccc}
\hline Compound & $\begin{array}{c}\text { Free energy of } \\
\text { binding (DOPC) }\end{array}$ & $\begin{array}{c}\text { Log of } \mathrm{PC}^{a}- \\
\mathrm{BLM}^{b}\end{array}$ & $\begin{array}{c}\text { Log of PC }- \\
\mathrm{BBB}^{c}\end{array}$ & $\begin{array}{c}\text { Log of PC }- \\
\text { Caco-2 }\end{array}$ & $\begin{array}{c}\text { Log of PC - } \\
\text { PAMPA }\end{array}$ \\
\hline BREQ & $-6.58 \mathrm{kcal} / \mathrm{mol}$ & 0.93 & -2.57 & -3.24 & -0.37 \\
$\mathbf{4 1}$ & $-5.38 \mathrm{kcal} / \mathrm{mol}$ & -0.76 & -3.16 & -3.67 & -1.93 \\
\hline
\end{tabular}

${ }^{a} \mathrm{PC}$, permeability coefficient

${ }^{b} \mathrm{BLM}$, bilipid membrane

${ }^{c} \mathrm{BBB}$, blood brain barrier 


\section{References}

[1] Chen, S.-F., Papp, L. M., Ardecky, R. J., Rao, G. V., Hesson, D. P., Forbes, M., and Dexter, D. L. (1990) Structure-activity relationship of quinoline carboxylic acids, Biochem. Pharmacol 40, 709-714.

[2] Davis, J. P., and Copeland, R. A. (1997) Histidine to alanine mutants of human dihydroorotate dehydrogenase, Biochem. Pharmacol 54, 459-465.

[3] Greene, S., Watanabe, K., Braatz-Trulson, J., and Lou, L. (1995) Inhibition of dihydroorotate dehydrogenase by the immunosuppressive agent leflunomide, Biochem. Pharmacol 50, 861-867.

[4] Papageorgiou, C., Zurini, M., Weber, H.-P., and Borer, X. (1997) Leflunomide's bioactive metabolite has the minimal structural requirements for the efficient inhibition of human dihydroorotate dehydrogenase, Bioorg. Chem 25, 233-238.

[5] Madak, J. T., Cuthbertson, C. R., Miyata, Y., Tamura, S., Petrunak, E. M., Stuckey, J. A., Han, Y., He, M., Sun, D., Showalter, H. D., and Neamati, N. (2018) Design, synthesis, and biological evaluation of 4-quinoline carboxylic acids as inhibitors of dihydroorotate dehydrogenase, J. Med. Chem 61, 5162-5186.

[6] Pimple, S. R. (2008) Flavonoids and related compounds as nucleoside transporter inhibitors, In Pharmaceutical Sciences, University of Tennessee, Theses and Dissertations (ETD).

[7] Toan, S. V., To, K. K., Leung, G. P., de Souza, M. O., Ward, J. L., and Tse, C. M. (2003) Genomic organization and functional characterization of the human concentrative nucleoside transporter-3 isoform (hCNT3) expressed in mammalian cells, Pflugers Arch 447, 195-204. 
[8] Hummel, C. S., Lu, C., Loo, D. D., Hirayama, B. A., Voss, A. A., and Wright, E. M. (2011) Glucose transport by human renal Na+/D-glucose cotransporters SGLT1 and SGLT2, Am. J. Physiol. Cell. Physiol 300, C14-21.

[9] Ward, J. L., Sherali, A., Mo, Z. P., and Tse, C. M. (2000) Kinetic and pharmacological properties of cloned human equilibrative nucleoside transporters, ENT1 and ENT2, stably expressed in nucleoside transporter-deficient PK15 cells, J. Biol. Chem 275, 8375-8381.

[10] Wang, C., Lin, W., Playa, H., Sun, S., Cameron, K., and Buolamwini, J. K. (2013) Dipyridamole analogs as pharmacological inhibitors of equilibrative nucleoside transporters. Identification of novel potent and selective inhibitors of the adenosine transporter function of human equilibrative nucleoside transporter 4 (hENT4), Biochem. Pharmacol 86, 1531-1540.

[11] Torphy, T. J., and Cieslinski, L. B. (1990) Characterization and selective inhibition of cyclic nucleotide phosphodiesterase isozymes in canine tracheal smooth muscle, Mol. Pharmacol 37, 206-214.

[12] Thomas, M. K., Francis, S. H., and Corbin, J. D. (1990) Characterization of a purified bovine lung cGMP-binding cGMP phosphodiesterase, J. Biol. Chem 265, 14964-14970.

[13] Lin, W., and Buolamwini, J. K. (2007) Synthesis, flow cytometric evaluation, and identification of highly potent dipyridamole analogues as equilibrative nucleoside transporter 1 inhibitors, J. Med. Chem 50, 3906-3920.

[14] Ehrenkranz, J. R., Lewis, N. G., Kahn, C. R., and Roth, J. (2005) Phlorizin: a review, Diabetes Metab. Res. Rev 21, 31-38.

[15] Gresele, P., Momi, S., and Falcinelli, E. (2011) Anti-platelet therapy: phosphodiesterase inhibitors, Br. J. Clin. Pharmacol 72, 634-646. 
[16] Lomize, A. L., Hage, J. M., Schnitzer, K., Golobokov, K., LaFaive, M. B., Forsyth, A. C., and Pogozheva, I. D. (2019) PerMM: A web tool and database for analysis of passive membrane permeability and translocation pathways of bioactive molecules, J Chem Inf Model 59, 3094-3099.

[17] Lomize, A. L., and Pogozheva, I. D. (2019) Physics-based method for modeling passive membrane permeability and translocation pathways of bioactive molecules, J Chem Inf Model 59, 3198-3213. 